\title{
A busca de informação sobre covid-19 na web: uma perspectiva cibermétrica
}

\author{
The search for information about covid-19 on the web: a cybermetric \\ perspective
}

\section{La búsqueda de información sobre covid-19 en la web: una perspectiva cibermetrica}

Felipe Lopes Roberto ${ }^{1, a}$

felipeiav269@gmail.com | https://orcid.org/o000-0001-5640-1573

Matheus Hingst Tavares ${ }^{1, a}$

matheus.football@gmail.com | https://orcid.org/oooo-00o1-6843-4372

Paula Carina de Araújoi,

paulacarina@ufpr.br | https://orcid.org/0000-0003-4608-752X

Maria do Carmo Duarte Freitas ${ }^{1, c}$

mcf@ufpr.br | https://orcid.org/0000-0002-7046-6020

José Marcelo Almeida Prado Cestari ${ }^{1, d}$

cestari@ufpr.br | https://orcid.org/0000-0002-6422-1609

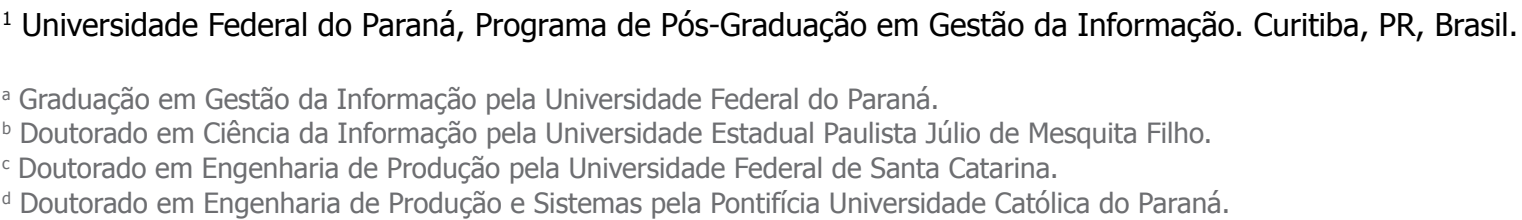

\section{RESUMO}

Objetivo: Demonstrar a influência da pandemia de covid-19 nas buscas realizadas no Google por meio do levantamento de dados em uma aplicação cibermétrica. Método: Estudo de aplicação cibermétrica que utiliza a ferramenta Google Trends e os termos 'covid-19', 'coronavírus', 'cloroquina' e 'vacina contra a covid-19', para o período de 31 de dezembro de 2019 a 17 de janeiro de 2021. Resultados: Reconhecer que as primeiras buscas pelo termo 'covid-19' ocorreram na mesma data do anúncio do primeiro caso confirmado. Ocorreu também o crescimento no volume de busca por informações sobre os sintomas de pneumonia relacionadas com a primeira morte por coronavírus. A intensificação nas consultas relativas a 'covid vaccine allergy' esteve associada ao início da vacinação no mundo. Conclusão: Em períodos de pandemia, a sociedade procura intensamente por informações relacionadas ao seu contexto e a busca pode ser motivada pelos meios de comunicação.

Palavras-chave: Cibermetria; Busca da informação; Sociedade da informação; Covid-19; Google Trends. 


\section{ABSTRACT}

Objective: It aims to show the influence of the covid-19 pandemic on the searches on Google, using the data survey in a cybermetric application. Method: It is a cybermetric study that uses the Google Trends tool by searching for 'covid-19', 'cononavírus', 'cloroquina' and 'vacina contra a covid-19' between December $31^{\text {st }}$, 2019, and January $17^{\text {th }}$, 2021. Results: It acknowledges that the first searches for the term 'covid-19' were made on the same day of the announcement of the first confirmed case. There was also a rise in the number of searches for information on symptoms of pneumonia related to the first death caused by coronavirus. The intensification in the searches related to 'covid vaccine allergy' was associated to the start of the vaccination in the world. Conclusion: In pandemic times, the society intensely searches for information related to their context and the searches can be motivated by the media.

Keywords: Cybermetrics; Information search; Information society; Covid-19; Google Trends.

\section{RESUMEN}

Objetivo: Demostrar la influencia de la pandemia de la covid-19 en las búsquedas realizadas en Google, mediante la recolección de datos en una aplicación cibermétrica. Método: Estudio de aplicación cibernética utilizando la herramienta Google Trends y los términos 'covid-19', 'coronavírus', 'cloroquina' y 'vacina contra a covid-19' para el período de 31 de diciembre de 2019 al 17 de enero de 2021. Resultados: Reconoce que las primeras búsquedas del término 'covid-19' ocurrieron en la misma fecha que el anuncio del primer caso confirmado. También hubo un aumento en el volumen de búsqueda de información sobre síntomas de neumonía relacionados con la primera muerte por coronavirus. La intensificación de las consultas relacionadas con la 'covid vaccine allergy' se asoció con el inicio de la vacunación en todo el mundo. Conclusión: En períodos de pandemia, la sociedad búsqueda de manera intensiva información relacionada con su contexto y puede ser motivada por los medios de comunicación.

Palabras clave: Cibermetría; Búsqueda de información; Sociedad de la Información; Covid-19; Google Trends.

Este artigo compõe o dossiê Estudos métricos da informação científica em saúde, parte 2.

Contribuição dos autores:

Concepção e desenho do estudo: Felipe Lopes Roberto; Matheus Hingst Tavares; Paula Carina de Araújo.

Aquisição, análise ou interpretação dos dados: Felipe Lopes Roberto; Matheus Hingst Tavares; Paula Carina de Araújo; Maria do Carmo Duarte Freitas.

Redação do manuscrito: Felipe Lopes Roberto; Matheus Hingst Tavares; Paula Carina de Araújo; Maria do Carmo Duarte Freitas. Revisão crítica do conteúdo intelectual: Felipe Lopes Roberto; Matheus Hingst Tavares; Paula Carina de Araújo; Maria do

Carmo Duarte Freitas; José Marcelo Almeida Prado Cestari.

Declaração de conflito de interesses: não há.

Fontes de financiamento: Coordenação de Aperfeiçoamento de Pessoal de Nível Superior (Capes).

Considerações éticas: não há.

Agradecimentos/Contribuições adicionais: Dr. Eduardo Silveira - Universidade Federal do Paraná.

Histórico do artigo: submetido: 19 maio 2021 | aceito: 09 dez. 2021 | publicado: 25 fev. 2022.

Apresentação anterior: não houve.

Licença CC BY-NC atribuição não comercial. Com essa licença é permitido acessar, baixar (download), copiar, imprimir, compartilhar, reutilizar e distribuir os artigos, desde que para uso não comercial e com a citação da fonte, conferindo os devidos créditos de autoria e menção à Reciis. Nesses casos, nenhuma permissão é necessária por parte dos autores ou dos editores. 


\section{INTRODUÇÃO}

Uma das características da sociedade da informação é a agilidade no acesso à informação buscada pelas pessoas por meio das Tecnologias da Informação e Comunicação (TICs) (TAKAHASHI, 2000). Diferentes contextos despertam variados interesses na busca por informação, derivados da necessidade dos indivíduos.

Com o passar dos anos, os meios de busca e o uso da informação foram se modificando, e as TICs se revelaram instrumentos que contribuem para que os indivíduos se mantenham constantemente informados. Nesse sentido, as TICs representam ferramentas para a propagação da informação nos tempos atuais e favorecem a comunicação e a reflexão acerca do papel da informação na sociedade (SILVA, 2018).

Partindo da compreensão de que "necessidade é uma demanda em potencial" (CUNHA; AMARAL; DANTAS, 2015, p. 4) e de que, no contexto informacional, essa necessidade representa as motivações para uma pessoa buscar, encontrar e usar a informação, apresenta-se aqui um estudo que busca responder qual é a influência da pandemia de covid-19 nas buscas realizadas no Google. Dessa forma, este estudo objetiva demonstrar a influência da pandemia de covid-19 nas buscas realizadas no Google por meio do levantamento de dados em uma aplicação cibermétrica.

A covid-19, infecção respiratória aguda grave causada pelo coronavírus SARS-CoV-2, tornou-se uma emergência sanitária mundial em janeiro de 2020 a partir de decisão da Organização Mundial da Saúde(OMS), ocorrendo o epicentro do surto na cidade de Wuhan, na província de Hubei, na China (YUEN et al., 2020).

Em um estudo, Silva e Gouveia (2019, p. 41) constataram que "a sociedade recorre intensamente à internet para buscar informações acerca de sintomas e formas de tratamento de diversos tipos de doenças, como meio de se inteirar dos assuntos e, possivelmente, compartilhar essas informações [...]”. Essa mesma pesquisa descreve o Google como a maior base de dados informacionais do mundo, a qual é tão rica em informações que tem servido de base para muitas pesquisas relacionadas.

Nesse contexto, a necessidade da sociedade de buscar informações em relação à covid-19 surgiu a partir da urgência dos indivíduos por compreenderem melhor a doença e seus principais sintomas e medicamentos, bem como entender como o vírus atua e é transmitido (FERENTZ et al., 2020).

Percebe-se que, em tempos de pandemia, a busca por informações acontece de modo desenfreado e acaba sendo permeada também por notícias falsas, que além de enganosas despertam uma inquietação informacional na sociedade (SILVA, 2018).

Portanto, é importante salientar que na área da saúde a veracidade das informações é um fator imprescindível. Destaca-se que a "qualidade e quantidade de informações disponibilizadas sobre saúde impacta diretamente na aceitação e no entendimento da própria sociedade, visto que o processo de comunicação entre mídia e seres humanos ocorre de forma unilateral, ou seja, não há troca de ideias [...]” (SILVA; GOUVEIA, 2019, p. 28).

Uma vez apresentados o contexto e o objetivo desta pesquisa na introdução, a próxima seção contempla a revisão de literatura sobre o tema abordado. Então, é descrita a trajetória metodológica percorrida para a realização do estudo acompanhada da apresentação e da análise dos dados. Por fim, apresentam-se as considerações finais e as referências.

\section{O COMPORTAMENTO DE BUSCA POR INFORMAÇÃO NO CONTEXTO DA PANDEMIA DE COVID-19}

Nesta seção, é caracterizado o conceito de comportamento informacional e são apresentados estudos recentes que analisaram o fenômeno da 'infodemia' relacionado ao comportamento informacional dos indivíduos. 
O estudo de Cruz (2018, p. 57) constata que a internet é um recurso informacional vasto e que oferece ferramentas de comunicação e de troca de fluxos informacionais cada vez mais presentes no dia a dia dos sujeitos informacionais. No entanto, ela é recente na história e, consequentemente, os estudos sobre ela também.

Furtado e Alcará (2015) consideram que compreender as características dos modelos de comportamento informacional contribui para os estudos que visam o desenvolvimento e a formação da competência na informação. O usuário precisa desenvolver habilidades informacionais específicas, uma vez que elas são prérequisitos para a busca de informação e a aquisição do conhecimento, ao mesmo tempo que se configuram uma espécie de simbiose relacionada ao desenvolvimento do comportamento informacional adequado para atingir o objetivo de acesso à informação.

Matos e Jacintho (2020, p. 182), ao analisarem a abordagem evolutiva do comportamento informacional a partir das bases epistemológicas da biblioteconomia e da ciência da informação presentes nos trabalhos de Amanda Spink e Armando Malheiros Silva, fazem uma crítica aos modelos de busca de informação com características tecnicistas como o de Nicholas Belkin. Os autores reconhecem a necessidade de uma atitude holística ou interdisciplinar para a compreensão do comportamento informacional.

O comportamento informacional é um conceito proveniente dos estudos sobre necessidade. Ele busca o uso da informação, que, com o avançar das décadas, passou a ser percebido de maneira mais ampla, ao abarcar elementos não somente cognitivos, como a percepção da lacuna de conhecimento diante de determinada situação, mas também ao considerar os fatores emocionais, como reações de confusão ou clareza, satisfação ou decepção, assim como os aspectos sociais, como as características demográficas e situacionais (VALE; PINTO; CÂNDIDO, 2019).

No contexto da pandemia da covid-19, o fenômeno denominado 'infodemia' tem se destacado. O termo se refere a um grande aumento no volume de informações associadas a um assunto específico, que podem se multiplicar exponencialmente em pouco tempo devido a um evento específico, como a pandemia atual. Nessa situação, também surgem rumores e desinformação, além da manipulação de informações com intenção duvidosa. Na era da informação, esse fenômeno é amplificado pelas mídias sociais - como um 'vírus', origem do nome infodemia, as informações se alastram mais rapidamente (OPAS, 2020; GARCIA; DUARTE, 2020). Nesse contexto, a atenção tem se voltado ao comportamento informacional dos indivíduos, de modo a reconhecer formas de minimizar os impactos da desinformação.

O excesso de informações, por vezes conflitantes, torna difícil encontrar aquelas que são verdadeiramente úteis para orientar as pessoas e pode dificultar a tomada de decisão por gestores e profissionais da saúde, especialmente quando não há tempo hábil para avaliar as evidências disponíveis. Ademais, o volume de informações que hoje alcança as pessoas por diversos meios e mídias (como televisão, rádio, computador, tablets, smartphones, jornais, blogs, mídias sociais, aplicativos de conversas) acaba por sobrecarregá-las (GARCIA; DUARTE, 2020).

Em uma pesquisa recente, no contexto da pandemia do coronavírus, Silva (2020) questionou: "Como ocorre a infodemia no Twitter durante a pandemia de covid-19 em 2020?". A autora concluiu que "tanta informação, verdadeira ou falsa, acaba não informando de fato os usuários-cidadãos, mas sim desorientandoos e deixando-os falsamente cientes. Isso notadamente ocorre no Twitter, sendo que todos os estudos analisados verificaram a grande quantidade de tuítes acerca da covid-19" (SILVA, 2020, p. 156-157).

Coelho, Morais e Rosa (2020) realizaram um estudo sobre as diversas estratégias de países que utilizaram o apoio das diferentes tecnologias da informação em saúde de massa para o enfrentamento de pandemias, controle e prevenção de situações de desastres naturais, com destaque para China, Itália, Estados Unidos, Letônia, Alemanha e Inglaterra. 
Os autores concluíram que a capacidade tecnológica brasileira é limitada de uma forma geral. Reconheceram ainda que o Brasil poderia se valer das diferentes experiências internacionais para uma melhor elaboração de planos estratégicos no enfrentamento de pandemias, com a devida adaptação à dinâmica populacional e à estrutura do Estado (COELHO; MORAIS; ROSA, 2020).

O estudo de Araújo e Oliveira (2020) questiona quais são os discursos acionados no compartilhamento de informação sobre a hidroxicloroquina nas redes sociais on-line. $\mathrm{O}$ foco da pesquisa foi o Twitter e possibilitou observar que "o debate público sobre desinformação transcende tentativas de classificação a partir de categorias estanques que buscam determinar o que é uma informação de qualidade ou de confiança ou o que é desinformação" (ARAÚJO; OLIVEIRA, 2020, p. 203).

A pesquisa também reconhece que fenômenos mais amplos estão envolvidos nesse contexto - mais especificamente, que "a informação científica se relaciona com politização da ciência e exercícios de pressão política nas tomadas de decisão relacionadas à saúde pública e a um processo de descrença e ataques às instituições promotoras ou disseminadoras de conhecimento" (ARAÚJO; OLIVEIRA, 2020, p. 203).

Cabe ainda citar a pesquisa de Santos et al. (2020), que objetivou caracterizar a infodemia da covid-19 no Brasil por meio do mapeamento das notícias falsas de grande circulação relacionadas à pandemia no contexto brasileiro e discutir o seu conteúdo a partir do letramento informacional. A pesquisa analisou dados de busca por determinados temas e comparou-os com as postagens em mídias sociais, como Twitter, Facebook e Instagram. O estudo conclui que há um cenário infodêmico no Brasil no contexto da pandemia de covid-19.

Portanto, esta pesquisa é desenvolvida em um contexto de excesso de informação, existência de desinformação, politização da ciência e crise de reconhecimento das instituições científicas em meio a uma pandemia. Soma-se a esse contexto a necessidade de informação dos cidadãos sobre uma nova doença que atinge o mundo todo, sobre os acontecimentos sociais e políticos relacionados a essa emergência sanitária.

Após esse contexto, reconhece-se a figura do cidadão que utiliza as ferramentas de busca, como o Google, para procurar informação e responder às suas necessidades informacionais e/ou curiosidades de forma rápida. E, devido ao intenso uso da web como fonte informacional sobre saúde, há um empenho dos motores de busca para "dispor informações mais íntegras e verídicas sobre as doenças que circundam a sociedade" (SILVA; GOUVEIA, 2019, p. 34).

Dessa forma, esta pesquisa pretende olhar para os contextos social e político do momento pandêmico por meio das notícias veiculadas pela imprensa e relacioná-las ao comportamento de buscas realizadas por meio do Google, a partir de uma perspectiva cibermétrica.

\section{METODOLOGIA}

Esta pesquisa caracteriza-se como exploratória quanto aos seus objetivos e fez uso da cibermetria no que diz respeito aos procedimentos. Os estudos cibermétricos foram abordados, inicialmente, por Ray Larson, que utilizou técnicas bibliométricas para analisar as características dos documentos na web (CURTY; DELBIANCO, 2020). E foi em 1997 que o termo se popularizou com a publicação do periódico Cybermetrics: International Journal of Scientometrics, Informetrics and Bibliometrics, que não está mais corrente (CURTY; DELBIANCO, 2020).

A cibermetria é conceituada como "o estudo dos aspectos quantitativos da construção e uso dos recursos de informação, estruturas e tecnologias em toda a internet, a partir de abordagens informétricas e bibliométricas" (BJÖRNEBORN, 2004, p. 13, tradução nossa).

Araújo (2015) aponta a internet, o ciberespaço, a web social e a World Wide Web como recursos de estudo da cibermetria. De forma mais específica, esse estudo métrico da informação preocupa-se com as comunicações formais e informais entre distintos grupos sociais e que constam registrados em bases de 
dados, páginas web, URLs, microblogs, blogs, salas de bate-papo, mailing lists, comunidades virtuais, grupos de discussão, entre outros.

Para a realização deste estudo, foi utilizado o Google Trends, ferramenta de acesso público que apresenta o cálculo das tendências de buscas sobre os temas de interesses, por meio de frequências de buscas no Google em determinado período. Essas buscas podem ser por cidade, estado, país ou em todo mundo, com período personalizado e categorias que englobam os mais diversos temas. Os algoritmos do Google Trends objetivam a normalização dos resultados dos volumes de busca com base na maior quantidade de busca para uma determinada situação. Essa escala de busca varia entre o (volume de buscas menor do que $1 \%$ em comparação com o pico) e 100 (maior volume de acessos) (GOOGLE, c2020).

Determinou-se o período para a coleta de dados entre 31 de dezembro de 2019 (data da primeira notificação à OMS da ocorrência de um surto de pneumonia na cidade de Wuhan, província de Hubei, República Popular da China) e 17 de janeiro de 2021 (data em que a primeira pessoa foi vacinada contra a covid-19 no Brasil). Os dados são apresentados em quatro tabelas, comparando acontecimentos/notícias no Brasil e em todo o mundo, com o objetivo de revelar indícios de alterações no comportamento informacional do usuário da web em tempos de pandemia.

Com o intuito de realizar uma análise de busca mais precisa no tópico de interesse, visto que os algoritmos do Google Trends relacionam, conforme sua interpretação, inúmeros termos de busca, optou-se pela seleção dos termos: 'covid-19', 'coronavírus', 'cloroquina' e 'vacina contra a covid-19'. Como critério para a seleção das notícias e dos acontecimentos decorrentes da pandemia da covid-19, a presente pesquisa fundamentou-se no portal de notícias G1 e no site do Ministério da Saúde, que divulgou uma linha do tempo com os principais eventos relacionados a essa temática.

Estabeleceu-se ainda, como parâmetro de busca, o período de 5 a 8 dias entre os acontecimentos em virtude das alterações de resultados que períodos maiores promoveriam com o surgimento de novos fatos. Com o propósito de refinar resultados mais pertinentes para a pesquisa, priorizaram-se as categorias de 'saúde' e 'todas as categorias', tendo como tipo de pesquisa a 'pesquisa na $w e b$ ', visto que a escolha de outras categorias e de diferentes tipos de pesquisa apresentavam resultados que não interessavam.

Para a apresentação dos resultados, são exibidos nas tabelas os cinco primeiros dados dos itens 'interesse por sub-região', 'assuntos relacionados' e 'consultas relacionadas'. A respeito dos resultados apontados pelo item 'interesse ao longo do tempo', optou-se por quatro ou cinco datas que demonstrassem a relação das notícias com as consultas no Google. Em cada tabela evidenciaram-se as notícias referentes à data selecionada, à estratégia de busca utilizada, mostrando-se os termos, as categorias, o período, o tipo de pesquisa e o país/a região.

\section{APRESENTAÇÃO E DISCUSSÃO DOS RESULTADOS}

A Tabela 1 apresenta a comparação entre o anúncio do primeiro caso de infecção pelo coronavírus relatado no Brasil e no restante do mundo. Segundo o portal de notícias G1, a Organização Mundial da Saúde (OMS) emitiu o primeiro alerta no dia 31 de dezembro de 2019, após as autoridades chinesas informarem sobre o cluster de casos de "pneumonia de causa desconhecida" na cidade de Wuhan, na China (CRONOLOGIA..., 2020). Nessa mesma data, percebe-se o aumento, apresentado pelo Google Trends, na busca pelo termo 'covid-19'. No Brasil, o primeiro caso foi notificado 57 dias após o primeiro alerta emitido pela OMS, notando-se, assim, um aumento na busca pelo termo 'coronavírus' no dia 26 de fevereiro de 2020.

Os resultados do Google Trends demonstram que, mundialmente, Hong Kong foi a sub-região que se destacou nas buscas relacionadas à covid-19 no período de 28 de dezembro de 2019 a 5 de janeiro de 2020. 
Entre os assuntos relacionados, 'pneumonia doença' foi o assunto mais recorrente, e 'pneumonia Wuhan', a consulta relacionada mais recorrente. No período indicado, o dia 5 de janeiro de 2020 teve o pico de interesse.

No Brasil, o estado do Amapá foi o que teve a maioria das buscas sobre a covid-19 no período de 23 de fevereiro de 2020 até 28 de fevereiro de 2020. 'covid-19' e 'caso coronavírus' foram as principais consultas relacionadas. No dia 26 de fevereiro de 2020, houve o pico de interesse pela temática, expresso pelas buscas.

Tabela 1 - Comparação entre o anúncio do primeiro caso de covid-19 no mundo e no Brasil ${ }^{1}$

\begin{tabular}{|c|c|c|c|c|c|c|}
\hline \multicolumn{7}{|c|}{ Descrição da busca } \\
\hline Data & Notícia/acontecimento & $\begin{array}{l}\text { Termos de } \\
\text { busca }\end{array}$ & $\begin{array}{l}\text { Período da } \\
\text { busca }\end{array}$ & Categoria & $\begin{array}{l}\text { Tipo de } \\
\text { pesquisa }\end{array}$ & $\begin{array}{l}\text { Região } \\
\text { /país }\end{array}$ \\
\hline $31 / 12 / 19$ & $\begin{array}{c}\text { China anunciava o primeiro } \\
\text { caso de contaminação pelo } \\
\text { novo coronavírus }\end{array}$ & Covid-19 & $\begin{array}{l}\text { de } 28 / 12 / 19 \\
\text { a } 05 / 01 / 20\end{array}$ & Saúde & $\begin{array}{l}\text { Pesquisa } \\
\text { na web }\end{array}$ & $\begin{array}{l}\text { Todo o } \\
\text { mundo }\end{array}$ \\
\hline \multicolumn{7}{|c|}{ Resultados Google Trends } \\
\hline $\begin{array}{l}\text { Interesse por } \\
\text { sub-região }\end{array}$ & Assuntos relacionados & \multicolumn{2}{|c|}{ Consultas relacionadas } & \multicolumn{3}{|c|}{ Interesse ao longo do tempo } \\
\hline $\begin{array}{l}1^{\circ} \text { Hong Kong } \\
2^{\circ} \text { China } \\
3^{\circ} \text { Macau } \\
4^{0} \text { Taiwan } \\
5^{\circ} \text { Singapura }\end{array}$ & $\begin{array}{c}1^{\circ} \text { Pneumonia doença } \\
2^{\circ} \text { Doenças infecciosas - } \\
\text { doenças } \\
3^{\circ} \text { Sintoma - assunto } \\
4^{0} \text { Coronavírus da síndrome } \\
\text { respiratória aguda grave } 2 \text { - } \\
\text { vírus } \\
5^{\circ} \text { Hong Kong - Região } \\
\text { administrativa especial }\end{array}$ & \multicolumn{2}{|c|}{$\begin{array}{l}10 \text { Pneumonia Wuhan } \\
2^{\circ} \text { Wuhan } \\
3^{\circ} \text { Pneumonia Wuhan }\end{array}$} & \multicolumn{3}{|c|}{$\begin{array}{l}30 / 12 / 19-\text { Covid }-19=00 \\
31 / 12 / 19-\text { Covid }-19=76 \\
02 / 01 / 20-\text { Covid }-19=66 \\
04 / 01 / 20-\text { Covid }-19=96 \\
05 / 01 / 20-\text { Covid- } 19=100\end{array}$} \\
\hline \multicolumn{7}{|c|}{ Descrição da busca } \\
\hline Data & Notícia/acontecimento & $\begin{array}{l}\text { Termos de } \\
\text { busca }\end{array}$ & $\begin{array}{l}\text { Período da } \\
\text { busca }\end{array}$ & Categoria & $\begin{array}{l}\text { Tipo de } \\
\text { pesquisa }\end{array}$ & $\begin{array}{c}\text { Região } \\
\text { /país }\end{array}$ \\
\hline $26 / 02 / 20$ & $\begin{array}{l}\text { Brasil confirma o primeiro } \\
\text { caso da covid-19 no país }\end{array}$ & $\begin{array}{l}\text { covid-19 } \\
\text { coronavírus }\end{array}$ & $\begin{array}{c}\text { de } 23 / 02 / 20 \\
\text { a } 28 / 02 / 20\end{array}$ & Saúde & $\begin{array}{c}\text { Pesquisa } \\
\text { na web }\end{array}$ & Brasil \\
\hline \multicolumn{7}{|c|}{ Resultados Google Trends } \\
\hline $\begin{array}{l}\text { Interesse por } \\
\text { sub-região }\end{array}$ & $\begin{array}{c}\text { Consultas relacionadas } \\
\text { (Covid-19) }\end{array}$ & \multicolumn{2}{|c|}{$\begin{array}{c}\text { Consultas relacionadas } \\
\text { (coronavírus) }\end{array}$} & \multicolumn{3}{|c|}{ Interesse ao longo do tempo } \\
\hline $\begin{array}{l}1^{\circ} \text { Amapá } \\
2^{\circ} \text { Rondônia } \\
3^{\circ} \text { Goiás } \\
4^{0} \text { Amazonas } \\
5^{\circ} \text { Ceará }\end{array}$ & $\begin{array}{l}1^{0} \text { Covid-19 } \\
2^{\circ} \text { Covid-19 }\end{array}$ & \multicolumn{2}{|c|}{$\begin{array}{l}1^{\circ} \text { Caso chikungunya } \\
2^{\circ} \text { Lolo coronavírus } \\
3^{\circ} \text { Coronavírus São Paulo } \\
4^{\circ} \text { Caso coronavírus no } \\
\text { Brasil } \\
5^{\circ} \text { Caso de coronavírus no } \\
\text { Brasil }\end{array}$} & \multicolumn{3}{|c|}{$\begin{array}{c}24 / 02 / 20-\text { Covid }-19=<1 / \\
\text { coronavírus }=12 \\
25 / 02 / 20-\text { Covid }-19=<1 / \\
\text { coronavírus }=20 \\
26 / 02 / 20-\text { Covid }-19=02 / \\
\text { coronavírus }=100 \\
27 / 02 / 20-\text { Covid }-19=01 / \\
\text { coronavírus }=74\end{array}$} \\
\hline
\end{tabular}

Fonte: elaboração dos autores.

A comparação entre os períodos de busca em relação à divulgação da primeira morte registrada pelo coronavírus na China e em São Paulo é demonstrada na Tabela 2. No dia 11 de janeiro de 2020, as autoridades de saúde da cidade de Wuhan anunciavam a primeira morte causada pela misteriosa "pneumonia viral" (DEUTSCHE WELLE, 2020). Observou-se o crescimento por consultas relacionadas aos 'sintomas de

1 A grafia de algumas palavras pode figurar de forma incorreta nos campos das 'consultas relacionadas' nas tabelas, porque foram reproduzidas da forma como foram buscadas pelos usuários.

2 Loló é uma mistura de éter e clorofórmio, considerada uma droga ilícita. Foram divulgadas notícias falsas afirmando que a droga era indicada para o tratamento de covid-19. 
pneumonia' e 'coronavírus' nas pesquisas realizadas no Google Trends, no período entre 5 e 13 de janeiro de 2020. Depois do primeiro registro de morte pela covid-19 no Brasil, constatou-se a expansão do volume de consultas por 'sintomas coronavírus covid-19'.

Tabela 2 - Comparação entre o anúncio da primeira morte por covid-19 no mundo e no Brasil

\begin{tabular}{|c|c|c|c|c|c|c|}
\hline \multicolumn{7}{|c|}{ Estratégia de busca } \\
\hline Data & Notícia/acontecimento & $\begin{array}{c}\text { Termos de } \\
\text { busca }\end{array}$ & $\begin{array}{c}\text { Período da } \\
\text { busca }\end{array}$ & Categoria & $\begin{array}{l}\text { Tipo de } \\
\text { pesquisa }\end{array}$ & $\begin{array}{c}\text { Região } \\
\text { /país }\end{array}$ \\
\hline $11 / 01 / 20$ & $\begin{array}{l}\text { China anunciava a primeira } \\
\text { morte oficialmente } \\
\text { registrada pelo novo } \\
\text { coronavírus }\end{array}$ & $\begin{array}{c}\text { covid-19 } \\
\text { coronavírus }\end{array}$ & $\begin{array}{c}\text { de } 05 / 01 / 20 \\
\text { a } 13 / 01 / 20\end{array}$ & Saúde & $\begin{array}{l}\text { Pesquisa } \\
\text { na web }\end{array}$ & $\begin{array}{l}\text { Todo o } \\
\text { mundo }\end{array}$ \\
\hline
\end{tabular}

\begin{tabular}{|c|c|c|c|}
\hline \multicolumn{4}{|c|}{ Resultados Google Trends } \\
\hline $\begin{array}{c}\text { Interesse por } \\
\text { sub-região }\end{array}$ & $\begin{array}{c}\text { Consultas relacionadas } \\
\text { (Covid-19) }\end{array}$ & $\begin{array}{c}\text { Consultas relacionadas } \\
\text { (coronavírus) }\end{array}$ & Interesse ao longo do tempo \\
\hline $\begin{array}{l}10 \text { Macau } \\
2^{\circ} \text { Hong Kong } \\
3^{\circ} \text { China } \\
4^{0} \text { Taiwan } \\
5^{\circ} \text { Coreia do Sul }\end{array}$ & $\begin{array}{l}1^{\circ} \text { Sintomas de pneumonia } \\
2^{\circ} \text { Sintomas de pneumonia } \\
\text { Wuhan } \\
3^{\circ} \text { Sintomas de pneumonia } \\
\text { Wuhan }\end{array}$ & $\begin{array}{l}1^{\circ} \text { Coronavírus } \\
2^{\circ} \text { Coronavírus recente } \\
3^{\circ} \text { Wuhan Coronavírus } \\
4^{0} \text { Veneno corona oc43 }\end{array}$ & $\begin{array}{l}\text { 09/01/20 }- \text { Covid }-19=31 / \\
\text { coronavírus }=100 \\
10 / 01 / 20-\text { Covid- } 19=17 / \\
\text { coronavírus }=45 \\
11 / 01 / 20-\text { Covid }-19=14 / \\
\text { coronavírus }=51 \\
12 / 01 / 20-\text { Covid }-19=13 / \\
\text { coronavírus }=31\end{array}$ \\
\hline
\end{tabular}

\begin{tabular}{|c|c|c|c|c|c|c|}
\hline \multicolumn{7}{|c|}{ Estratégia de busca } \\
\hline Data & Notícia/acontecimento & $\begin{array}{l}\text { Termos de } \\
\text { busca }\end{array}$ & $\begin{array}{l}\text { Período da } \\
\text { busca }\end{array}$ & Categoria & $\begin{array}{l}\text { Tipo de } \\
\text { pesquisa }\end{array}$ & $\begin{array}{l}\text { Região } \\
\text { /país }\end{array}$ \\
\hline $17 / 03 / 20$ & $\begin{array}{c}\text { São Paulo registra } 10 \text { morte } \\
\text { pelo novo coronavírus no } \\
\text { Brasil }\end{array}$ & $\begin{array}{l}\text { Covid-19 } \\
\text { coronavírus }\end{array}$ & $\begin{array}{l}\text { de } 15 / 03 / 20 \\
\text { a } 19 / 03 / 20\end{array}$ & Saúde & $\begin{array}{l}\text { Pesquisa } \\
\text { na web }\end{array}$ & Brasil \\
\hline \multicolumn{7}{|c|}{ Resultados Google Trends } \\
\hline $\begin{array}{l}\text { Interesse por } \\
\text { sub-região }\end{array}$ & $\begin{array}{c}\text { Consultas relacionadas } \\
\text { (Covid-19) }\end{array}$ & $\begin{array}{r}\text { Consultas r } \\
\text { (coron }\end{array}$ & $\begin{array}{l}\text { elacionadas } \\
\text { avírus) }\end{array}$ & \multicolumn{3}{|c|}{ Interesse ao longo do tempo } \\
\hline $\begin{array}{l}1^{\circ} \text { Distrito Federal } \\
2^{\circ} \text { Acre } \\
3^{\circ} \text { Amapá } \\
4^{\circ} \text { Rio de Janeiro } \\
5^{\circ} \text { Espírito Santo }\end{array}$ & $\begin{array}{c}1^{0} \text { Sintomas Coronavírus } \\
\text { Covid-19 } \\
2^{\circ} \text { Ibuprofeno Covid-19 } \\
3^{\circ} \text { Vacina covid- } 19 \text { china } \\
4^{0} \text { Vacina para covid-19 } \\
5^{0} \text { covid-19 symptoms }\end{array}$ & \multicolumn{2}{|c|}{$\begin{array}{c}1^{0} \text { Sintomas Coronavírus } \\
\text { covid-19 } \\
2^{\circ} \text { Coronavirus piaui } \\
3^{\circ} \text { Ibuprofeno } \\
\text { Coronavírus } \\
4^{\circ} \text { Sintomas do } \\
\text { Coronavírus } \\
5^{\circ} \text { Plataforma ivis } \\
\text { coronavirus }\end{array}$} & \multicolumn{3}{|c|}{$\begin{array}{l}16 / 03 / 20-\text { Covid- } 19=03 / \\
\text { coronavírus }=76 \\
17 / 03 / 20-\text { Covid- } 19=04 / \\
\text { coronavírus }=95 \\
18 / 03 / 20-\text { Covid- } 19=05 / \\
\text { coronavírus }=95 \\
19 / 03 / 20-\text { Covid- } 19=05 / \\
\text { coronavírus }=100\end{array}$} \\
\hline
\end{tabular}

Fonte: elaboração dos autores.

A Tabela 3 apresenta os resultados das pesquisas referentes aos termos 'covid-19' e 'coronavírus' no período em que ocorreram os anúncios dos diagnósticos de covid-19 dos presidentes Donald Trump e Jair Bolsonaro. Mazui (2020) informou que em 7 de julho de 2020 o presidente Jair Bolsonaro testou positivo para covid-19. No espaço entre 5 e 9 de julho de 2020, constatou-se o aumento pela busca do termo 'coronavírus', ocorrendo também um acréscimo nas pesquisas a respeito de 'Bolsonaro com coronavírus'. Durante o intervalo de cinco dias, em que foi noticiado o teste positivo de Donald Trump para covid-19, o termo 'coronavírus' foi o mais procurado no dia 2 de outubro de 2020. 
Tabela 3 - Comparação entre os anúncios dos testes positivos para covid-19 dos presidentes Jair Bolsonaro e Donald Trump

\begin{tabular}{|c|c|c|c|c|c|c|}
\hline \multicolumn{7}{|c|}{ Estratégia de busca } \\
\hline Data & Notícia/acontecimento & $\begin{array}{l}\text { Termos de } \\
\text { busca }\end{array}$ & $\begin{array}{l}\text { Período da } \\
\text { busca }\end{array}$ & Categoria & $\begin{array}{l}\text { Tipo de } \\
\text { pesquisa }\end{array}$ & $\begin{array}{l}\text { Região } \\
\text { /país }\end{array}$ \\
\hline $11 / 01 / 20$ & $\begin{array}{l}\text { Jair Bolsonaro testa positivo } \\
\text { para covid-19 }\end{array}$ & $\begin{array}{l}\text { Cloroquina } \\
\text { Coronavírus }\end{array}$ & $\begin{array}{l}\text { de } 05 / 07 / 20 \\
\text { a } 09 / 07 / 20\end{array}$ & $\begin{array}{l}\text { Todas as } \\
\text { categorias }\end{array}$ & $\begin{array}{l}\text { Pesquisa } \\
\text { na web }\end{array}$ & Brasil \\
\hline \multicolumn{7}{|c|}{ Resultados Google Trends } \\
\hline $\begin{array}{l}\text { Interesse por } \\
\text { sub-região }\end{array}$ & $\begin{array}{c}\text { Consultas relacionadas } \\
\text { (cloroquina) }\end{array}$ & \multicolumn{2}{|c|}{$\begin{array}{c}\text { Consultas relacionadas } \\
\text { (coronavírus) }\end{array}$} & \multicolumn{3}{|c|}{ Interesse ao longo do tempo } \\
\hline $\begin{array}{l}10 \text { Mato Grosso } \\
\text { do Sul } \\
2^{\circ} \text { Roraima } \\
3^{\circ} \text { Tocantins } \\
4^{0} \text { Espírito Santo } \\
5^{\circ} \text { Rondônia }\end{array}$ & $\begin{array}{c}1^{0} \text { Cloroquina } \\
2^{\circ} \text { Bolsonaro cloroquina } \\
3^{\circ} \text { Cloroquina coronavírus } \\
4^{0} \text { Cloroquina bula } \\
5^{\circ} \text { Cloroquina para que } \\
\text { serve }\end{array}$ & \multicolumn{2}{|c|}{$\begin{array}{l}10 \text { Bolsonaro com } \\
\text { coronavírus } \\
\text { Bolsonaro coronavírus } \\
\text { positivo } \\
30 \text { Bolsonaro esta com } \\
\text { Coronavírus } \\
40 \text { Bolsonaro está com } \\
\text { Coronavírus } \\
\text { Bolsonaro com corona }\end{array}$} & \multicolumn{3}{|c|}{$\begin{array}{l}\text { 05/07/20 }- \text { Cloroquina }=02 / \\
\text { coronavírus }=76 \\
06 / 07 / 20-\text { Cloroquina }=01 / \\
\text { coronavírus }=75 \\
07 / 07 / 20-\text { Cloroquina }=06 / \\
\text { coronavírus }=100 \\
08 / 07 / 20-\text { Cloroquina }=06 / \\
\text { coronavírus }=69\end{array}$} \\
\hline \multicolumn{7}{|c|}{ Estratégia de busca } \\
\hline Data & Notícia/acontecimento & $\begin{array}{l}\text { Termos de } \\
\text { busca }\end{array}$ & $\begin{array}{l}\text { Período da } \\
\text { busca }\end{array}$ & Categoria & $\begin{array}{l}\text { Tipo de } \\
\text { pesquisa }\end{array}$ & $\begin{array}{l}\text { Região } \\
\text { /país }\end{array}$ \\
\hline $02 / 10 / 20$ & $\begin{array}{l}\text { Donald Trump vai para } \\
\text { hospital após diagnóstico } \\
\text { de covid-19 }\end{array}$ & $\begin{array}{l}\text { Covid-19 } \\
\text { coronavírus }\end{array}$ & $\begin{array}{l}\text { de } 1 / 10 / 20 \\
\text { a } 04 / 10 / 20\end{array}$ & Saúde & $\begin{array}{l}\text { Pesquisa } \\
\text { na web }\end{array}$ & $\begin{array}{l}\text { Estados } \\
\text { Unidos }\end{array}$ \\
\hline \multicolumn{7}{|c|}{ Resultados Google Trends } \\
\hline $\begin{array}{l}\text { Interesse por } \\
\text { sub-região }\end{array}$ & $\begin{array}{c}\text { Consultas relacionadas } \\
\text { (Covid-19) }\end{array}$ & $\begin{array}{r}\text { Consultas } \mathbf{r} \\
\text { (coron }\end{array}$ & $\begin{array}{l}\text { elacionadas } \\
\text { avírus) }\end{array}$ & \multicolumn{3}{|c|}{ Interesse ao longo do tempo } \\
\hline $\begin{array}{l}1^{0} \text { Dakota do Sul } \\
2^{\circ} \text { Nebraska } \\
3^{\circ} \text { Luisiana } \\
40 \text { Kansas } \\
5^{\circ} \text { Arkansas }\end{array}$ & $\begin{array}{c}1^{\circ} \text { Trump covid symptoms } \\
2^{\circ} \text { Trump covid test positive } \\
3^{\circ} \text { Trump has covid } \\
4^{\circ} \text { Trump tests positive } \\
\text { covid } \\
5^{\circ} \text { Trump tested positive for } \\
\text { covid }\end{array}$ & $\begin{array}{r}1^{\circ} \text { Trump c } \\
\text { upc } \\
2^{\circ} \text { Trump } \\
\text { coron } \\
3^{\circ} \text { Does tr } \\
\text { coron } \\
4^{\circ} \text { Trump has } \\
5^{\circ} \text { Presid } \\
\text { coron }\end{array}$ & $\begin{array}{l}\text { oronavirus } \\
\text { late } \\
\text { positive } \\
\text { avirus } \\
\text { ump have } \\
\text { avirus } \\
\text { coronavirus } \\
\text { ent Trump } \\
\text { avirus }\end{array}$ & \multicolumn{3}{|c|}{$\begin{array}{l}01 / 10 / 20-\text { Covid }-19=45 / \\
\text { coronavírus }=51 \\
02 / 10 / 20-\text { Covid- } 19=79 / \\
\text { coronavírus }=100 \\
03 / 10 / 20-\text { Covid }-19=67 / \\
\text { coronavírus }=84 \\
04 / 10 / 20-\text { Covid- } 19=59 / \\
\text { coronavírus }=68\end{array}$} \\
\hline
\end{tabular}

Fonte: elaboração dos autores.

Objetivando entender os resultados a respeito das regiões mais interessadas por notícias referentes à contaminação dos presidentes Jair Bolsonaro e Donald Trump pelo vírus covid-19, fez-se a relação entre os dados apresentados no estudo e os estados em que o então candidato do PSL e o então candidato do Partido Republicano obtiveram a maior porcentagem de votos. Em 2018, o atual presidente do Brasil derrotou Fernando Haddad, no segundo turno, com 55,13\% dos votos, conquistando a vitória em 16 estados e 21 capitais (MAPA..., 2018).

Em 2016, o ex-presidente dos Estados Unidos Donald Trump contraria as pesquisas e as previsões da Agência Associated Press vencendo a candidata do Partido Democrata, Hillary Clinton, tornando-se, na ocasião, o $45^{\circ}$ presidente eleito no país (DONALD..., 2016). Associando as cinco regiões mais interessadas na notícia sobre o teste positivo de Donald Trump para covid-19, percebe-se que elas foram as localidades em que o Partido Republicano obteve vantagem em relação ao Partido Democrata, tendo o percentual de 
61,5\% em Dakota do Sul, 60,6\% em Arkansas, 59,9\% em Nebraska, 58,1\% em Luisiana e 57,0\% no estado do Kansas (CABLE NEWS NETWORK, 2016).

No dia 8 de dezembro de 2020, o portal de notícias G1 noticiou sobre a primeira pessoa vacinada contra a covid-19 no Reino Unido (IDOSA..., 2020). No período de 6 a 10 de dezembro de 2020, verifica-se a intensificação nas consultas relativas a 'covid vaccine allergy', assim como o aumento do interesse pelo termo 'covid-19'. Depois de 40 dias do anúncio da primeira pessoa vacinada contra covid-19 no mundo, o Brasil registra a aplicação da primeira dose da CoronaVac, em São Paulo (MACHADO et al., 2020). Identificou-se o crescimento em consultas relacionadas a 'vacina aprovada covid' entre os dias 15 e 19 de janeiro de 2020.

Tabela 4-Comparação entre o anúncio da primeira aplicação da vacina contra covid-19 no mundo e no Brasil

\begin{tabular}{|c|c|c|c|c|c|c|}
\hline \multicolumn{7}{|c|}{ Descrição da busca } \\
\hline Data & Notícia/acontecimento & $\begin{array}{l}\text { Termos de } \\
\text { busca }\end{array}$ & $\begin{array}{l}\text { Período da } \\
\text { busca }\end{array}$ & Categoria & $\begin{array}{l}\text { Tipo de } \\
\text { pesquisa }\end{array}$ & $\begin{array}{l}\text { Região } \\
\text { /país }\end{array}$ \\
\hline $08 / 12 / 20$ & $\begin{array}{l}\text { Primeira pessoa no mundo } \\
\text { vacinada contra covid-19 }\end{array}$ & $\begin{array}{l}\text { Covid-19 } \\
\text { Vacina contra } \\
\text { Covid-19 }\end{array}$ & $\begin{array}{l}\text { de } 06 / 12 / 20 \\
\text { a } 10 / 12 / 20\end{array}$ & Saúde & $\begin{array}{l}\text { Pesquisa } \\
\text { na web }\end{array}$ & $\begin{array}{l}\text { Todo o } \\
\text { mundo }\end{array}$ \\
\hline
\end{tabular}

\begin{tabular}{cccc} 
& \multicolumn{3}{c}{ Resultados Google Trends } \\
Interesse por & Consultas relacionadas & Consultas relacionadas & Interesse ao longo do tempo \\
sub-região & (Covid-19) & $\begin{array}{c}\text { (vacina contra a } \\
\text { Covid-19) }\end{array}$ &
\end{tabular}

$\begin{array}{lc}1^{\circ} \text { Itália } & 1^{\circ} \text { Covid vaccine allergy } \\ 2^{\circ} \text { Polônia } & 2^{\circ} \text { Reactions to covid vaccine } \\ 3^{\circ} \text { Brasil } & 3^{\circ} \text { Mrna impfstoff covid } \\ 40 \text { Portugal } & 4^{\circ} \text { Covid } 19 \text { erectile } \\ 5^{\circ} \text { Turquia } & \text { dysfunction } \\ & 5^{\circ} \text { Covit belirtileri }\end{array}$

$1^{\circ}$ Allergic reaction covid vaccine

$2^{\circ}$ Fda covid vaccine side effects

30 Reactions to covid vaccine

40 Covid vaccine reaction uk

50 Covid 19 vaccine side effects fda

\begin{tabular}{|c|c|c|c|c|c|c|}
\hline \multicolumn{7}{|c|}{ Estratégia de busca } \\
\hline Data & Notícia/acontecimento & $\begin{array}{l}\text { Termos de } \\
\text { busca }\end{array}$ & $\begin{array}{l}\text { Período da } \\
\text { busca }\end{array}$ & Categoria & $\begin{array}{l}\text { Tipo de } \\
\text { pesquisa }\end{array}$ & $\begin{array}{l}\text { Região } \\
\text { /país }\end{array}$ \\
\hline $17 / 01 / 21$ & $\begin{array}{l}\text { Primeira pessoa vacinada } \\
\text { contra a covid-19 no Brasil }\end{array}$ & $\begin{array}{l}\text { Covid-19 } \\
\text { coronavírus }\end{array}$ & $\begin{array}{c}\text { de } 15 / 01 / 21 \\
\text { a } 19 / 01 / 21\end{array}$ & Saúde & $\begin{array}{l}\text { Pesquisa } \\
\text { na web }\end{array}$ & Brasil \\
\hline
\end{tabular}

\begin{tabular}{|c|c|c|c|}
\hline \multicolumn{4}{|c|}{ Resultados Google Trends } \\
\hline $\begin{array}{l}\text { Interesse por } \\
\text { sub-região }\end{array}$ & $\begin{array}{c}\text { Consultas relacionadas } \\
\text { (Covid-19) }\end{array}$ & $\begin{array}{c}\text { Consultas relacionadas } \\
\text { (coronavírus) }\end{array}$ & Interesse ao longo do tempo \\
\hline $\begin{array}{l}\text { 10 Roraima } \\
2^{\circ} \text { Amapá } \\
3^{\circ} \text { Rio Grande } \\
\text { do Norte } \\
4^{\circ} \text { Distrito } \\
\text { Federal } \\
5^{\circ} \text { Pará }\end{array}$ & $\begin{array}{l}1^{\circ} \text { Vacina aprovada covid } \\
2^{\circ} \text { Kit fura fila vacina covid } \\
3^{\circ} \text { Vacinação são paulo covid } \\
4^{\circ} \text { Vacinas covid brasil } \\
5^{\circ} \text { Comorbidades covid }\end{array}$ & $\begin{array}{c}1^{\circ} \text { Coronavirus em manaus } \\
2^{\circ} \mathrm{G} 1 . \text { com.br coronavírus } \\
3^{\circ} \text { Efeitos colaterais da } \\
\text { vacina do corona } \\
4^{\circ} \text { Nova variante do } \\
\text { coronavírus } \\
5^{\circ} \text { Quantos dias duram os } \\
\text { sintomas do corona }\end{array}$ & $\begin{array}{c}16 / 01 / 21-\text { Covid- } 19=56 / \\
\text { Coronavírus }=23 \\
17 / 01 / 21-\text { Covid- } 19=87 / \\
\text { Coronavírus }=32 \\
18 / 01 / 21-\text { Covid- } 19=100 / \\
\text { Coronavírus }=27 \\
19 / 01 / 21-\text { Covid- } 19=89 / \\
\text { Coronavírus }=26\end{array}$ \\
\hline
\end{tabular}

Fonte: elaboração dos autores. 
Durante a pandemia, inúmeras manifestações de negacionismo e de desinformação têm sido noticiadas na mídia e permeiam os diferentes meios de comunicação e, por consequência, afetam a população, contrariando órgãos competentes como a OMS e o próprio Ministério da Saúde (ARRUDA, 2021). O presidente brasileiro mostrou-se contrário às instituições tradicionais, especialmente a imprensa e a ciência, que, naquele momento, disseminavam informações a respeito de formas de prevenção e riscos de contágio (FERNANDES et al., 2020). No mesmo período em que foi divulgada a notícia sobre a primeira pessoa vacinada no Brasil, a rede bolsonarista, que consiste, segundo Ratier (2020), em grupos políticos de WhatsApp criados para apoiar o presidente Jair Bolsonaro, compartilhou uma notícia falsa referente à enfermeira Mônica Aparecida Calazans, a primeira pessoa a ser vacinada contra a covid-19 no Brasil, afirmando que a enfermeira já tinha tomado doses da CoronaVac e que a imunização foi encenada (DOMINGOS, 2021).

Tal comportamento, que contribui para a disseminação de informações falsas, tem tornado os apoiadores do atual governante do país vítimas do próprio negacionismo, com as regiões em que moram figurando nas primeiras posições do ranking dos estados em que ocorreu o maior número de mortes por covid-19 (COSTA; SARDINHA, 2021). Esses dados assemelham-se aos apresentados no presente estudo, na Tabela 4, e indicam os estados de Roraima, Amapá e Distrito Federal entre os que mais buscaram informação sobre covid-19 ou coronavírus no mesmo período. Esses estados foram redutos eleitorais do presidente Jair Bolsonaro no primeiro turno da última eleição presidencial, conforme a Tabela 5 .

Na Tabela 5, percebe-se que em Roraima, Rondônia, Mato Grosso do Sul e Espírito Santo, estados situados em quatro das cinco regiões mais interessadas pelo assunto, segundo a ferramenta Google Trends, Bolsonaro alcançou mais de 50\% dos votos no primeiro turno (MAPA..., 2018).

Tabela 5 - Votação em Bolsonaro e mortes por covid-19

\begin{tabular}{lcccc}
$\begin{array}{c}\text { Unidade } \\
\text { federativa }\end{array}$ & $\begin{array}{c}\text { Partido do } \\
\text { governador }\end{array}$ & $\begin{array}{c}\text { óbitos por } \\
\text { covid-19 }\end{array}$ & $\begin{array}{c}\text { Mortes por 100 } \\
\text { mil habitantes } \\
\text { até 6/04/2021 }\end{array}$ & $\begin{array}{c}\text { Votos em } \\
\text { Bolsonaro } \\
\text { em \% }\end{array}$ \\
\hline Amazonas & PSC & 12.136 & 292,8 & 41,14 \\
Rondônia & PSL & 4.368 & 245,8 & 58,94 \\
Mato Grosso & DEM & 8.081 & 231,9 & 55,81 \\
Roraima & PSL & 1.362 & 224,8 & 60,70 \\
Rio de Janeiro & PSC & 38.040 & 220,3 & 53,88 \\
Distrito Federal & MDB & 6.449 & 213,9 & 55,27 \\
Espírito Santo & PSB & 7.862 & 195,6 & 50,45 \\
Rio Grande do Sul & PSDB & 21.018 & 184,7 & 49,04 \\
Goiás & DEM & 12.119 & 172,7 & 52,57 \\
São Paulo & PSDB & 78.554 & 171,1 & 47,73 \\
Mato Grosso do Sul & PSDB & 4.571 & 164,5 & 51,99 \\
Santa Catarina & PSL & 11.548 & 161,2 & 61,32 \\
Ceará & PT & 14.692 & 160,9 & 20,23 \\
Amapá & PDT & 1.346 & 159,2 & 39,13 \\
\hline
\end{tabular}

Fonte: Costa e Sardinha (2021).

No mês de janeiro de 2021, o Brasil teve 29,5 mil mortes por covid-19, alcançando naquele momento o total de 224.534 óbitos. O presente estudo demonstrou que Roraima foi o estado que mais buscou informações na web a respeito da covid-19 entre os dias 15 e 19 de janeiro de 2021. Relacionando esse fato ao contexto do país, durante esse mês, percebe-se que o estado apresentava uma tendência de alta 
diária na média móvel de mortes por covid-19 desde 18 de janeiro (Figura 1). No dia 30 do mesmo mês, o Hospital Geral do estado atingiu a superlotação de leitos clínicos, não havendo leitos de UTI disponíveis (PINHEIRO, 2021).

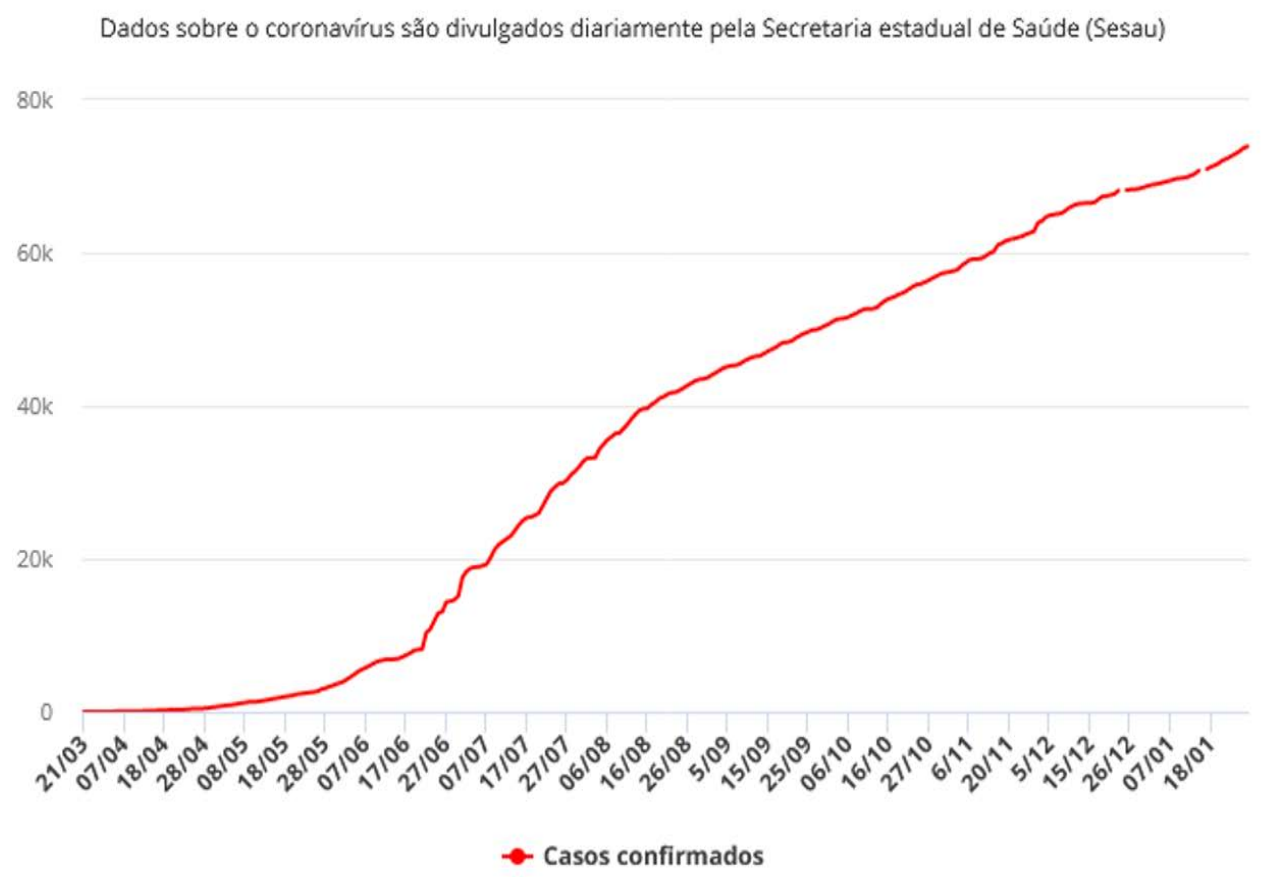

Figura 1 - Evolução da covid-19 em Roraima

Fonte: Hospital... (2021).

Goulart e Muñoz (2020) realizaram uma pesquisa qualitativa sobre desinformação e pós-verdade, investigando as práticas informacionais em redes sociais, no contexto de pandemia. $\mathrm{O}$ cenário exposto pelos autores foi de incerteza da população diante do grande volume de informações que contribuem para a desinformação. Com a finalidade de identificar os interesses e as práticas dos internautas em rede sociais, empregou-se o método de netnografia - o estudo das interações sociais através da tecnologia. A pesquisa revelou alterações no comportamento dos usuários dos grupos públicos do Facebook, devido a fatores emocionais, a posicionamento ideológico e a visão de mundo. Nessa pesquisa, também foi possível verificar a influência dos contextos social e econômico no comportamento de busca por informações.

Alencar et al. (2020) também utilizaram a plataforma Google Trends com o objetivo de verificar o comportamento de buscas on-line a respeito de informações sobre o novo coronavírus no Brasil. Buscaram uma relação com os casos e os óbitos e identificaram que, ao utilizarem o termo 'chikungunya', sem acento, a plataforma apresentou maior número de buscas. A pesquisa foi realizada abrangendo o período de 72 dias a partir do primeiro caso confirmado da doença no país.

Em um estudo com o objetivo de compreender o comportamento informacional da sociedade brasileira diante das epidemias de dengue, chikungunya e zika no Brasil nos anos de 2016 e 2017, os resultados encontrados corroboram com o presente estudo no que tange ao maior número de buscas por informações na web em decorrência do aumento de casos das doenças no período do verão, no qual ocorre a maior proliferação do mosquito transmissor das doenças dengue, chikungunya e zika (SILVA, 2018).

Este estudo buscou apontar indicadores que evidenciassem a modificação no comportamento de busca pelo tema covid-19, objetivo semelhante ao dos pesquisadores Garcias et al. (2020), que por meio de uma pesquisa qualitativa, utilizando o software Facepager, analisaram o engajamento dos seguidores da página oficial da Prefeitura Municipal de Curitiba no Facebook, no contexto de pandemia da covid-19. Os resultados 
das análises dos tipos de conteúdo e mídia adotados pela prefeitura reforçam as evidências desta pesquisa, demonstrando o crescimento de publicações, simultaneamente com o número de casos e óbitos registrados. Dessa forma, percebeu-se que, em momentos de crise, os gestores locais deveriam realizar análises nas ferramentas de uso público, visando compreender o alcance da informação.

\section{CONSIDERAÇÕES FINAIS}

Este estudo fez uma exploração a partir de recursos cibermétricos sobre o comportamento de busca de informação em saúde no contexto da pandemia de covid-19, valendo-se da ferramenta Google Trends. Percebeu-se que o negacionismo, característica presente atualmente nos contextos nacional e internacional, pode influenciar o comportamento de busca por informações. Constatou-se que alguns estados que votaram em sua maioria no atual presidente da República coincidem com aqueles que mais buscaram informações sobre a pandemia do coronavírus.

Infere-se que é preciso atenção para o desenvolvimento de ações que visem minimizar o compartilhamento de desinformação, pois ele pode afetar diretamente a vida de pessoas leigas. Dessa forma, percebe-se a importância da orientação com relação à competência informacional, à identificação de notícias falsas e ao combate às práticas criminosas de promoção da desinformação.

A quantidade e a intensidade das notícias veiculadas nas diversas mídias aumentam significativamente em tempos de pandemia. Esse aumento acaba contribuindo para a mudança no comportamento de busca por informações on-line, como foi visto no presente estudo. Por meio da normalização dos dados dos volumes de busca realizados pelos algoritmos do Google Trends, constatou-se que os resultados alcançaram os maiores volumes de acesso no período de busca estipulado.

Esta pesquisa demonstrou que com o aumento de casos as pessoas passaram a procurar mais por informações relacionadas à pandemia do coronavírus. Esse fato foi observado no estado de Roraima, o qual também apresentou uma tendência de alta diária na média móvel de mortes por covid-19 desde janeiro, ao mesmo tempo que foi o estado que mais buscou informações sobre a covid-19 nesse mês.

É importante salientar também que quem procura informações de saúde na web não necessariamente também irá procurar ajuda médica. Por outro lado, constatou-se que essas buscas na web estão relacionadas às notícias veiculadas naquele período, como, por exemplo, sintomas e tratamentos.

Como limitações, verificou-se a escassez de pesquisas que permitissem inter-relação com o presente estudo, bem como a identificação da real motivação dos usuários ao realizar buscas na $w e b$ a respeito da covid-19. Essa verificação seria possível com o uso de outros métodos para reconhecer as motivações dos usuários.

Para pesquisas futuras, sugere-se a análise do comportamento informacional com relação às notícias sobre a Comissão Parlamentar de Inquérito (CPI) da covid-19 veiculadas na web. Percebe-se ainda potencial para análise do comportamento informacional com relação às notícias veiculadas, após a vacinação de grande parte da população. As duas possibilidades de pesquisas podem apresentar diferentes perspectivas que complementem este estudo.

\section{REFERÊNCIAS}

ALENCAR, Delmo de Carvalho et al. Busca de informações sobre o novo coronavírus no Brasil: uma análise da tendência considerando as buscas on-line. Acta Paulista de Enfermagem, São Paulo, v. 33, p. 1-8, 2020. DOI: http://dx.doi.org/10.37689/acta-ape/2020EDT0004. Disponível em: https://www.arca.fiocruz.br/bitstream/ icict/46904/2/BuscalnfoCoronavirusBrasil.pdf. Acesso em: 19 maio 2021.

ARAÚJO, Ronaldo Ferreira de. Estudos métricos da informação na web e o papel dos profissionais da informação. Bibliotecas Universitárias: pesquisas, experiências e perspectivas, Belo Horizonte, v. 2, p. 42-64, 2015. Disponível em: http://hdl.handle.net/20.500.11959/brapci/17094. Acesso em: 19 maio 2021. 
ARAÚJO, Ronaldo Ferreira; OLIVEIRA, Thaiane Moreira de. Desinformação e mensagens sobre a hidroxicloroquina no Twitter: da pressão política à disputa científica. AtoZ: novas práticas em informação e conhecimento, Curitiba, v. 9, n. 2, p. 196-205, 8 dez. 2020. DOI: http://dx.doi.org/10.5380/atoz.v9i2.75929. Disponível em: https://revistas.ufpr.br/atoz/article/view/75929. Acesso em: 05 maio 2021.

ARRUDA, Robson Lima de. O negacionismo como artefato da pós-verdade: Bolsonaro, a pandemia e a educação. Boletim de Conjuntura (BOCA), Boa Vista, v. 5, n. 15, p. 81-93, 2021. Disponível em: https:// revista.ioles.com.br/boca/index.php/revista/article/view/259/238. Acesso em: 13 maio 2021.

BJÖRNEBORN, Lennart. Small-World Link Structures across an Academic Web Space: a library and information science approach. 2004. 469 p. Tese (Doutorado em Ciência da Informação) - Royal School of Library and Information Science, Copenhagen, 2009.

CABLE NEWS NETWORK. Presidential results. CNN, [s. I.], 2016. Election 2016. Disponível em: https:// edition.cnn.com/election/2016/results/president. Acesso em: 13 maio 2021.

COELHO, Akeni Lobo; MORAIS, Indyara de Araujo; ROSA, Weverton Vieira da Silva. A utilização de tecnologias da informação em saúde para o enfrentamento da pandemia do covid-19 no Brasil. Cadernos Ibero-Americanos de Direito Sanitário, Brasília, DF, v. 9, n. 3, p. 183-199, jul./set. 2020. DOI: https://doi. org/10.17566/ciads.v9i3.709. Disponível em: https://www.cadernos.prodisa.fiocruz.br/index.php/cadernos/ article/view/709/754. Acesso em: 08 dez. 2020.

COSTA, Sylvio; SARDINHA, Edson. Estados "bolsonaristas" lideram mortes por covid-19. Congresso em Foco, Brasília, DF, 15 abr. 2021. Governo. Disponível em: https://congressoemfoco.uol.com.br/saude/estadosbolsonaristas-lideram-mortes-por-covid-19/. Acesso em: 13 maio 2021.

CRONOLOGIA da expansão do novo coronavírus descoberto na China. G1, [s. I.], 22 jan. 2020. Ciência e Saúde. Disponível em: https://g1.globo.com/ciencia-e-saude/noticia/2020/01/22/cronologia-da-expansao-donovo-coronavirus-descoberto-na-china.ghtml. Acesso em: 12 mar. 2021.

CRUZ, Ruleandson do Carmo. Proposta teórico-metodológica para o estudo de sujeitos informacionais usuários de sites de redes sociais virtuais. Revista Brasileira de Educação em Ciência da Informação, São Paulo, v. 5, n. 1, p. 47-62, 2018. Disponível em: http://hdl.handle.net/20.500.11959/brapci/72841. Acesso em: 01 maio 2021.

CUNHA, Murilo Bastos da; AMARAL, Sueli Angelica do Amaral; DANTAS, Edmundo Brandão. Manual de estudo de usuários da informação. São Paulo: Atlas, 2015. 448 p.

CURTY, Renata Gonçalves; DELBIANCO, Natalia Rodrigues. As diferentes metrias dos estudos métricos da informação: evolução epistemológica, inter-relações e representações. Encontros Bibli: revista eletrônica de biblioteconomia e ciência da informação, Florianópolis, v. 25, p. 01-21, 20 out. 2020. DOI: https:// doi.org/10.5007/1518-2924.2020.e74593. Disponível em: https://periodicos.ufsc.br/index.php/eb/article/ view/74593. Acesso em: 28 out. 2020

DEUTSCHE WELLE. China tem $1^{\mathrm{a}}$ morte por misteriosa pneumonia viral. G1, [s. I.], 11 jan. 2020. Mundo. Disponível em: https://g1.globo.com/mundo/noticia/2020/01/11/china-tem-1a-morte-por-misteriosa-pneumoniaviral.ghtml. Acesso em: 12 mar. 2021.

DOMINGOS, Roney. É \#FAKE que enfermeira, $1^{\text {a }}$ a ser vacinada no Brasil, já tinha tomado doses da CoronaVac e que imunização foi encenada. G1, [s. I.], 18 jan. 2021. Fato ou Fake. Disponível em: https:// g1.globo.com/fato-ou-fake/coronavirus/noticia/2021/01/18/e-fake-que-enfermeira-1a-a-ser-vacinada-no-brasilja-tinha-tomado-doses-da-coronavac-e-que-imunizacao-foi-encenada.ghtml. Acesso em: 15 maio 2021.

DONALD Trump vence Hillary Clinton e é eleito presidente dos EUA. G1, São Paulo, 09 nov. 2016. Mundo. Disponível em: http://g1.globo.com/mundo/eleicoes-nos-eua/2016/noticia/2016/11/donald-trump-vence-hillaryclinton-e-e-eleito-presidente-dos-eua.html. Acesso em: 13 maio 2021.

FERENTZ, Larissa Maria da Silva et al. Pesquisa em tempos de coronavírus: publicações das universidades brasileiras durante a pandemia. Revista Tecnologia e Sociedade, Curitiba, v. 16, n. 43, p. 87-96, 2020. DOI: http://dx.doi.org/10.3895/rts.v16n43.12364. Disponível em: https://periodicos.utfpr.edu.br/rts/article/view/12364. Acesso em: 13 dez. 2020. 
FERNANDES, Carla Montuori et al. A pós-verdade em tempos de Covid-19: o negacionismo no discurso de Jair Bolsonaro no Instagram. Liinc em Revista, Rio de Janeiro, v. 16, n. 2, p. e5317-e5317, 2020. DOI: https:// doi.org/10.18617/liinc.v16i2.5317. Disponível em: http://revista.ibict.br/liinc/article/view/5317. Acesso em: 13 maio 2021

FURTADO, Renata Lira., ALCARÁ, Adriana Rosecler. Modelos de comportamento informacional: uma análise de suas características. In: SEMINÁRIO CIENTÍFICO ARQUIVOLOGIA E BIBLIOTECONOMIA, 4., 2015, Marília. Anais [...] Marília: UNESP, 2015. Disponível em: https://www.marilia.unesp.br/Home/Eventos/2015/se minariodearquivologiaebiblioteconomia/furtado-r.l..pdf. Acesso em: 15 abr. 2021.

GARCIA, Leila Posenato; DUARTE, Elisete. Infodemia: excesso de quantidade em detrimento da qualidade das informações sobre a covid-19. Epidemiologia e serviços de saúde, Brasília, DF, v. 29, n. 4, p. e2020186, 2020. DOI: https://doi.org/10.1590/S1679-49742020000400019. Disponível em: http://www.scielo. $\mathrm{br} / \mathrm{scielo}$.php?script=sci arttext\&pid=\$2237-96222020000400100\&lng=após\&nrm=após. Acesso em: 08 dez. 2020.

GARCIAS, Carlos Mello et al. O engajamento dos usuários do Facebook em relação à comunicação da covid-19: uma análise da Prefeitura Municipal de Curitiba (Paraná, Brasil). Liinc em Revista, Rio de Janeiro, v. 16, n. 2, p. e5353, 31 dez. 2020. DOI: https://doi.org/10.18617/liinc.v16i2.5353. Disponível em: http://revista. ibict.br/liinc/article/view/5353. Acesso em: 16 mar. 2021.

GOOGLE. Google Trends, [s. I.], c2020. Página inicial. Disponível em: https://trends.google.com/trends/. Acesso em: 18 maio 2020.

GOULART, Andrea; KAFURE, Ivette. Desinformação e pós-verdade no contexto da pandemia da covid-19: um estudo das práticas informacionais no Facebook. Liinc em Revista, Rio de Janeiro, v. 16, n. 2, 2020. DOI: https://doi.org/10.18617/liinc.v16i2.5397. Disponível em: http://revista.ibict.br/liinc/article/view/5397. Acesso em: 15 nov. 2021

HOSPITAL Geral de Roraima atinge superlotação de leitos clínicos e não há leitos de UTI disponíveis. G1, Boa Vista, 30 jan. 2021. Roraima. Disponível em: https://g1.globo.com/rr/roraima/noticia/2021/01/30/hospital-geralde-roraima-atinge-superlotacao-de-leitos-clinicos-e-após-após-leitos-de-uti-disponiveis.ghtml. Acesso em: 13 maio 2021.

IDOSA de 90 anos é a primeira a ser vacinada contra covid-19 no Reino Unido. G1, [s. I.], 8 dez. 2020. Bem Estar. Disponível em: https://g1.globo.com/bemestar/vacina/noticia/2020/12/08/idosa-de-90-anos-e-a-primeiraa-ser-vacinada-contra-covid-no-reino-unido.ghtml. Acesso em: 12 mar. 2021.

MACHADO, Lívia et al. Logo após aprovação da Anvisa, governo de SP aplica em enfermeira a $1^{\text {a }}$ dose de vacina contra Covid-19 no Brasil. G1, São Paulo, 17 jan. 2021. São Paulo. Disponível em: https://g1.globo. com/sp/após-paulo/noticia/2021/01/17/após-aprovacao-da-anvisa-governo-de-sp-aplica-1 ${ }^{\text {a }}$-dose-da-coronavacantes-do-inicio-do-plano-nacional-de-vacinacao.ghtml. Acesso em: 12 mar. 2021.

MAPA de presidente: quem ganhou em cada estado no $2^{\circ}$ turno. Gazeta do Povo, Curitiba, 28 out. 2018. Eleições 2018. Disponível em: https://especiais.gazetadopovo.com.br/eleicoes/2018/resultados/mapa-eleitoralde-presidente-por-estados-2turnol. Acesso em: 13 maio 2021.

MATOS, José Claudio Morelli; JACINTHO, Eliana Maria Santos Bahia. Algumas consequências da abordagem evolutiva para o campo de estudos do comportamento informacional. Logeion: Filosofia da Informação, Rio de Janeiro, v. 7, n. 1, p. 165-185, 2020. DOI: https://doi.org/10.21728/logeion.2020v7n1.p165-185. Disponível em: http://revista.ibict.br/fiinf/article/view/5388. Acesso em: 13 abr. 2021.

MAZUI, Guilherme. Bolsonaro anuncia resultado positivo de teste de covid-19 e diz que está "perfeitamente bem". G1, Brasília, DF, 07 jul. 2020. Política. Disponível em: https://g1.globo.com/politica/noticia/2020/07/07/ bolsonaro-diz-que-seu-exame-para-covid-19-deu-positivo.ghtml. Acesso em: 12 mar. 2021.

ORGANIZAÇÃO PAN-AMERICANA DA SAÚDE (OPAS). Fichas Informativas covid-19: entenda a infodemia e a desinformação na luta contra a covid-19. Brasília, DF: Organização Pan-Americana da Saúde, 2020. Disponível em: https://iris.paho.org/handle/10665.2/52054?locale-attribute=pt. Acesso em: 07 dez. 2020.

PINHEIRO, Lara. Brasil tem 29,5 mil mortes por covid-19 em janeiro; número é o terceiro maior desde o início da pandemia. G1, [s. I.], 01 fev. 2021. Bem Estar. Disponível em: https://g1.globo.com/bemestar/coronavirus/ noticia/2021/02/01/brasil-tem-295-mil-mortes-por-covid-19-em-janeiro-numero-e-o-terceiro-maior-desde-oinicio-da-pandemia.ghtml. Acesso em: 13 maio 2021. 
RATIER, Rodrigo Pelegrini. Império opaco: mapeamento da expansão da Rede Bolsonarista no WhatsApp. Verbum: Cadernos de Pós-Graduação, São Paulo, v. 9, n. 2, p. 42-58, 2020. Disponível em: https://revistas. pucsp.br/verbum/article/view/49942. Acesso em: 15 maio 2021.

SANTOS, Alana Driziê Gonzatti dos et al. Letramento informacional, covid-19 e infodemia. Liinc em Revista, Rio de Janeiro, v. 16, n. 2, p. e5214-e5214, 11 dez. 2020. DOI: https://doi.org/10.18617/liinc.v16i2.5214. Disponível em: http://revista.ibict.br/liinc/article/view/5214. Acesso em: 06 maio 2021.

SILVA, Ilaydiany Cristina Oliveira da. Rastreando epidemias na web: uma análise do comportamento informacional da sociedade brasileira mediante das epidemias de dengue, chikungunya e zika a partir do método webmétrico. 306 f. Tese (Doutorado em Ciência da Informação) - Universidade Federal do Rio de Janeiro, Rio de Janeiro, 2018. Disponível em: https://ridi.ibict.br/handle/123456789/997. Acesso em: 06 dez. 2020.

SILVA, llaydiany Oliveira da; GOUVEIA, Fabio Castro. A busca e o acesso às informações sobre saúde no contexto tecnológico. Conhecimento em Ação, Rio de Janeiro, v. 4, n. 2, jul./dez., 2019, p. 23-45. DOI: https:// doi.org/10.47681/rca.v4i2.29085. Disponível em: https://revistas.ufri.br/index.php/rca/article/view/29085/17720. Acesso em: 07 dez. 2020.

SILVA, Pietra Vaz Diógenes da. Pandemia e infodemia nas mídias: análise da desordem informacional no Twitter. AtoZ: novas práticas em informação e conhecimento, Curitiba, v. 9, n. 2, p. 148-159, 2020. DOI: http://dx.doi.org/10.5380/atoz.v9i2.76506. Disponível em: https://revistas.ufpr.br/atoz/article/view/76506. Acesso em: 05 maio 2021.

TAKAHASHI, Tadao (org). Sociedade da informação no Brasil: livro verde. Brasília, DF: Ministério da Ciência e Tecnologia, 2000.

VALE, Mariene Alves do; PINTO, Marli Dias de Souza; CÂNDIDO, Ana Clara. Gestão da informação e comportamento informacional nas organizações. In: ENCONTRO NACIONAL DE PESQUISA EM CIÊNCIA DA INFORMAÇÃO, 20., 2019. Anais [...]. Florianópolis, SC: UFSC, 2019. Disponível em: http://hdl.handle. net/20.500.11959/brapci/124395. Acesso em: 10 abr. 2021.

WERTHEIN, Jorge. A sociedade da informação e seus desafios. Ciência da Informação, Brasília, DF, v. 29, n. 2, p. 71-77, maio/ago., 2000. Disponível em: https://www.scielo.br/pdf/ci/v29n2/a09v29n2.pdf. Acesso em: 06 dez. 2020.

YUEN, Kit-San et al. SARS-CoV-2 and covid-19: The most important research questions. Cell \& Bioscience, Londres, v. 10, n. 40, p. 1-5, 2020. DOI: https://doi.org/10.1186/s13578-020-00404-4. Disponível em: https:// cellandbioscience.biomedcentral.com/articles/10.1186/s13578-020-00404-4. Acesso em: 12 dez. 2020. 